\title{
Comte: el científico y el reformador social*
}

\author{
Rafael Silva Vega**
}

Recibido: 30 de enero de 2017 - Aprobado: 27 de marzo de 2017

\section{Resumen}

A casi 170 años de su publicación, ¿qué tiene que decirnos hoy el Discurso sobre el espíritu positivo de Comte? ¿Cómo leer hoy ese pequeño tratado que, sin ser una de las obras más ambiciosas de Comte, es no solo por la que se le recuerda al autor, sino la que, además, ha obrado como motivo de inspiración de la ciencia social moderna? Este artículo asume el Discurso sobre el espíritu positivo como una obra de síntesis del pensamiento y del arduo trabajo intelectual de Comte. $Y$, en tal sentido, como la mejor evidencia de las tensiones entre el científico y el cura laico de una utopía sociológica que fue Comte. Este enfoque nos permitirá confrontar tanto la lectura que han hecho los practicantes y defensores del positivismo comtiano, como la que han elaborado sus detractores de la escuela de Frankfurt -Adorno y Horkheimer-.

Palabras clave: Comte; positivismo; ciencia social; sociología; utopía social

Este es un artículo de investigación y es producto del proyecto de investigación "La libertad en Maquiavelo: las posibilidades de la ciudadanía en sociedades en conflicto", adscrito al grupo Nexos -Grupo interdisciplinario de estudios socioculturales y psicológicos- de la Facultad de Derecho y Ciencias Sociales de la Universidad Icesi de Cali, y financiado por esta misma institución, cuyo investigador principal es Rafael Silva Vega. DOI: http://dx.doi.org/10.15332/ s0120-8454.2017.0091.08

* Director de la Maestría en Estudios Sociales y Políticos y profesor de tiempo completo e investigador del Departamento de Estudios Políticos de la Facultad de Derecho y Ciencias Sociales de la Universidad Icesi de Cali. PhD en Ciencias Sociales con Especialización en Estudios Políticos, Flacso. Magister en Filosofia y Licenciado en Filosofía Universidad del Valle. Correo electrónico: rsilva1@icesi.edu.co Dirección postal: 25608. ORCID: orcid.org/0000-0002-9180-0251 


\section{Comte: scientist and social reformer ${ }^{*}$}

Rafael Silva Vega**

\section{A bstract}

Almost 170 years after its publication, what has to say today's Discourse on the Positive Spirit by Comte? How to read this little treatise today, not being one of the most ambitious of Comte's works, is not only that you will remember the author but it has also acted as a source of inspiration for modern social science? This article assumes the Discourse on the Positive Spirit as a work of synthesis of thought and hard intellectual Comte's work. And in this regard, as the best evidence of tensions between the scientific and the lay priest sociological utopia was Comte. Approach will allow us to have reading confront practitioners and advocates of Comte's positivism, as they have developed their detractors Frankfurt School, Adorno and Horkheimer.

Keywords: Comte; positivism; social science; sociology; social utopia

This is a research article and is the outcome of the research project "Freedom in Machiavelli: the possibilities of citizenship in societies in conflict", appointed to the group Nexos - Interdisciplinary group of socio-cultural and psychological studies - of the Faculty of Law and Social Sciences of the Icesi University of Cali, and financed by this same institution, whose main researcher is Rafael Silva Vega. DOI: http://dx.doi.org/10.15332/s0120-8454.2017.0091.08

* Director of the Master's Degree in Social and Political Studies and full-time professor and researcher in the Department of Political Studies of the Faculty of Law and Social Sciences of the Icesi University of Cali. Doctor of Social Sciences with Specialization in Political Studies, Flacso. Master's Degree in Philosophy and Graduate in Philosophy from University of Valle. E-mail: rsilva1@icesi.edu.co Mailing address: 25608. ORCID: orcid.org/0000-0002-9180-0251 


\title{
Comte: le scientifique et réformateur social*
}

\author{
Rafael Silva Vega**
}

\section{Résumé}

À presque 170 ans de sa publication, qu'est-ce-que le Discours sur l'Esprit Positif d'Auguste Comte à a nous dire? Comment lire aujourd'hui ce petit traité, qui sans être l'une des œuvres les plus ambitieuses de Comte, est celle qui rappelle le plus l'auteur, mais également celle qui agit comme source d'inspiration de la science sociale moderne? Cet article assume le Discours sur l'Esprit Positif comme une oeuvre de synthèse de la pensée et du travail intellectuel acharné de Comte. Et dans ce sens, comme la meilleure preuve des tensions entre le scientifique et le prêtre laïque d'une utopie sociologique que fut Comte. Cette approche nous permettra de confronter à la fois la lecture qu'ont fait les praticiens et les défenseurs du positivisme de Comte, comme celle qu'ont fait ses détracteurs de l'École de Francfort, Adorno et Horkheimer.

Mots clés: Comte; positivisme; science sociale; sociologie; utopie sociale

* Cet article de recherche est un produit du projet de rechercher «La liberté chez Machiavel: les possibilités de la citoyenneté dans les sociétés en conflit», adscrit au groupe Nexos -Groupe interdisciplinaire d'Études Socio-culturelles et Psychologiques- de la Faculté de Droit et Sciences Sociales de I'Université Icesi de Cali, et financé par cette même institution, dont le chercheur principal est Rafael Silva Vega. DOI: http://dx.doi.org/10.15332/s0120-8454.2017.0091.08

** Directeur de la Maîtrise en Études Sociales et Politique, professeur à temps complet et chercheur du Département d'Études Politiques de la Faculté de Droit et Sciences Sociales de I'Université Icesi de Cali. PhD en Sciences Sociales avec une spécialisation en Études Politique, Flacso. Magister en Philosophie et Licence en Philosophie de I'Université del Valle. Email: rsilva1@icesi.edu.co. Adresse postale: 25608. ORCID: orcid.org/0000-0002-9180-0251 


\section{Introducción}

Este trabajo es una revisita a la filosofía positivista de Isidore Marie Auguste François Xavier Comte, nacido en Montpellier, Francia, el 19 de enero de 1798 y muerto en París, el 5 de septiembre de 1857. El objetivo central consiste en una relectura del Discurso sobre el espíritu positivo, pero en diálogo con las obras anteriores y posteriores a este famoso opúsculo que escribiera el autor.

Dos preguntas iniciales dirigieron el objetivo de este trabajo: a casi 170 años de su publicación, ¿qué tiene que decirnos hoy el Discurso sobre el espíritu positivo de Comte? y ¿cómo leer hoy ese pequeño tratado que, sin ser una de las obras más ambiciosas de Comte, es no solo por la que se le recuerda al autor, sino la que, además, ha obrado como motivo de inspiración de la ciencia social moderna? En relación con estas preguntas está articulada la preocupación de que es común que a los jóvenes estudiantes de las ciencias humanas y sociales se les presente a Comte como el padre de la sociología. De una ciencia positiva, que rechaza la metafísica, es decir la filosofía, por no atenerse a los hechos, al dato. Sin embargo, parece que nunca se ha caído en la cuenta de que la manera menos provechosa del leer a Comte en su Discurso sobre el espíritu positivo es a través de esta interpretación canónica, convertida en un relato oficial que pasa de generación en generación sin ser revisado de forma crítica. Por lo tanto, el propósito de este trabajo es indicar otro camino de lectura de esta pequeña obra del autor francés. En este sentido, lo que aquí se propone es que el Discurso sobre el espíritu positivo es una obra de síntesis del pensamiento y del arduo trabajo intelectual de Comte. Y que la dificultad de una obra así es comparable a la de obras como El Príncipe de Maquiavelo o el Discurso del método de Descartes. Pequeñas obras que transformaron al mundo, la mayoría de las veces desde lecturas parcializadas, esencialistas. De esta forma, lo que se propone aquí es una lectura no esencialista del autor. Por eso, en este trabajo se asume que el Discurso sobre el espíritu positivo es una obra de síntesis y, al mismo tiempo, la evidencia del desgarrador conflicto intelectual de Comte. La idea es entenderla como el signo de las tensiones entre el científico y el reformador social que fue Comte, entre el padre de la ciencia social moderna y el cura laico de una utopía sociológica. La explicación de esta tensión la encontraremos en un hecho histórico de gran relevancia tanto para Comte como para sus contemporáneos: la Revolución francesa. Como Tocqueville, Comte no compartió la Revolución francesa por considerar que la ideología revolucionaria conducía a los franceses a la servidumbre en la igualdad más que a la libertad. En este sentido su positivismo es, en parte, una reacción crítica al estado de cosas sociales que construyó la Revolución. Y, en tal sentido, un programa de reforma social para un mundo mejor. Este camino de lectura nos mostrará que la sociología comtiana nace de una profunda necesidad de construir un ideal social, al mejor estilo de Platón. Y nos permitirá sugerir, sin desarrollar esta idea, que si damos por aceptada esta tesis, ella nos debe llevar a confrontar la lectura que de Comte han hecho los practicantes y defensores del positivismo comtiano, así como la que han elaborado sus detractores de la escuela de Frankfurt-Adorno y Horkheimer-. 
Es decir, la idea de que en Comte la sociología no es un saber emancipador de la humanidad.

Siguiendo este hilo conductor, este trabajo está dividido en tres partes. La primera está dedicada a reconstruir los argumentos centrales del Discurso sobre el espíritu positivo. La idea es leer esta pequeña obra en una especie de shake que nos permita, en un movimiento de sacudida intencionado, sacar a la luz las tesis del doble proyecto de Comte con su filosofía positiva. Por un lado, científico y, por el otro, el de reforma social. La segunda parte está dedicada a pensar la posible tensión y la relación, en el autor, entre ciencia y utopía social. Esto se hará desde un diálogo entre las tesis centrales del Discurso sobre el espíritu positivo, reconstruidas en la primera parte de este trabajo, y las obras anteriores y posteriores a este opúsculo. Nos referimos en concreto a La science sociale (1972), Corso di filosofia positiva (2008), The Positive Philosophy (2009a), A General View of Positivism (2009b). La razón por la cual se han usado las traducciones de estas obras en inglés y en italiano ha sido porque se trata de ediciones críticas de gran calidad. Del mismo modo, cuando se cita de ellas se ha preferido no traducir al castellano para que el lector emprenda su propia traducción de los textos y pueda darle sentido a los argumentos que se ofrecen en este trabajo. La tercera parte está dedicada a un corto análisis, a modo de conclusión, de la crítica de Adorno y Horkheimer al positivismo comtiano que nos permitan construir un camino de confrontación con la lectura que han hecho los defensores y detractores de Comte.

\section{Breve reconstrucción de la idea del positivismo en Comte}

Augusto Comte publicó su Discurso sobre el espíritu positivo en 1844. Como recuerda Julián Marías, se trataba de la introducción al Tratado filosófico de astronomía popular que había compuesto el autor con posterioridad a su Sistema de filosofía positiva (Marías, 2007, p. 2). Esta pequeña obra puede ser comparada, por su trascendencia, con el Discurso del método de Descartes (2001) o El Príncipe de Maquiavelo (1998). Pues, pese a ser opúsculos y tener naturaleza de manuales, estas pequeñas obras terminaron por transformar el mundo en términos epistemológicos, metodológicos y científicos. Es decir, fueron escritos revolucionarios en el sentido que le da Kuhn (1975) al termino de "revoluciones científicas".

El opúsculo de Comte está compuesto de tres partes. La primera está dedicada a mostrar la "superioridad mental del espíritu positivo". La segunda a plantear la "superioridad social del espíritu positivo". Y la tercera, a revisar las "condiciones de advenimiento de la escuela positiva". Así, siguiendo el orden propuesto por el mismo Comte, la primera parte de este ensayo está dedicada a reconstruir las ideas y argumentos básicos que ofrece el autor en su Discurso con el fin de aislar, de forma más rigurosa, los puntos gruesos que serán problematizados en la segunda parte de este trabajo. 


\section{Primera parte: superioridad mental del espíritu positivo}

En la primera parte de su obra, al estilo de la mejor moda ilustrada, Comte se dedica a explicar la "evolución de la humanidad" (Comte, 2007, p. 2) apelando al recurso de una idea del progreso en sentido teleológico de fuertes ecos kantianos y hegelianos. Una paradójica manera de argumentar del padre del positivismo. Esta marcha del progreso se da, para él, tanto en el individuo como en la especie, como una ley que, inexorablemente, empuja a la humanidad al perfeccionamiento intelectual y social. Y se expresa en "tres estados teóricos", el primero preparatorio (teológico), el segundo transitorio (metafísico) y el tercero que es denominado como el "régimen definitivo de la razón humana" (positivo), es decir, el fin de la historia. Con lo cual, extrañamente, el positivismo es hijo de un supuesto metafísico: la ley de los tres estados. Por lo tanto, esta ley explica las distintas etapas, históricas y mentales -justo en este doble sentido-, del desarrollo, para Comte evolutivo, del pensamiento y la naturaleza del entendimiento humano sobre el mundo natural y social.

En términos generales, Comte caracteriza así al estado teológico, primer momento histórico y mental por el que inicia la evolución intelectual del individuo y de la especie:

En su primer despliegue, necesariamente teológico, todas nuestras especulaciones muestran espontáneamente una predilección característica por las cuestiones más insolubles, por los temas más radicalmente inaccesibles a toda investigación decisiva [...] en una palabra, los conocimientos absolutos. (Comte, 2007, p. 2)

Si bien la característica inicial del estado preparatorio es la explicación de lo "insoluble" y la búsqueda de los "conocimientos absolutos", esta explicación y búsqueda tiene su propia evolución dentro de él. El fetichismo, el politeísmo y el monoteísmo son como el alfa y la omega del primer estadio. Es decir, el despegar de la comprensión del mundo, sujeta a la imaginación como instrumento para la explicación, o sea el momento de lo ficticio que con su etapa final -el monoteísmo- enuncia la primera restricción de la imaginación y, con este límite, la decadencia de este estado inicial. En la lógica de Comte, la evolución del entendimiento humano es el de un continuo progreso intelectual hacia mejor. Pero este progreso se explica a través de un determinismo histórico que hace que el paso por los distintos estados teóricos obedezca a una necesidad histórica. Así como para Marx era necesario que la humanidad pasara por el capitalismo antes de llegar al fin de la historia con el comunismo, para Comte el estadio teológico es un momento histórico y mental necesario para "constituir primitivamente ciertas doctrinas comunes, sin las que el vínculo social no habría podido adquirir ni extensión ni consistencia, ya suscitando espontáneamente la única autoridad espiritual que pudiera entonces surgir" (Comte, 2007, p. 5).

En un movimiento dialéctico de negar-conservando, el estado metafísico mantiene el interés por lo "insoluble" y por los "conocimientos absolutos", pero rechaza 
el recurso a la imaginación. Eso lo hace distinto del teológico. Su recurso ahora es el "razonamiento" (Comte, 2007, p. 5), que deja de lado a los seres sobrenaturales y los reemplaza por entidades abstractas como principio de la explicación del mundo. Su objeto de comprensión último ya no es lo sobrenatural o Dios, sino la "naturaleza, como entidad general" (Comte 2007, p. 5) Sin embargo, este estado teórico es "transitorio", pues solo es capaz de una "actividad critica o disolvente" (Comte 2007, p. 6) con respecto a lo mental y a lo social. Es decir, es incapaz de construir un vínculo social. En tal sentido, apunta más a la anarquía que al orden social. Así, el estado metafísico no es más que una suerte de "enfermedad crónica" de la evolución mental del individuo y de la especie (Comte, 2007, p. 6).

Al contrario de los momentos anteriores, el estado positivo o real, etapa definitiva de la historia, consiste en la subordinación de la imaginación a la observación. Este estado establece como principio básico que "toda proposición que no puede reducirse estrictamente al mero enunciado de un hecho, particular o general, no puede ofrecer ningún sentido real e inteligible" (Comte, 2007, p. 7). El estado positivo implica, por ende, la renuncia a lo "insoluble", a la conquista de lo "absoluto, y, en tal sentido, privilegia solo lo que nos está dado conocer tanto en el mundo físico como en el social, o sea, "las diversas conexiones naturales" (Comte, 2007, p. 7). Ahora, la búsqueda está enfocada a lo que "es" relativo a nuestro mundo sin importar el problema del origen, de la esencia de las cosas. Y esto es así para los conocimientos humanos en general, pues ellos son, por naturaleza, sociales ya que son producto de una "evolución colectiva y continua" de la humanidad (Comte, 2007, p. 8). Pero esto, al tiempo, significa que la explicación de la realidad solo tiene sentido y eficacia cuando se sigue la huella de la invariabilidad de las leyes naturales. Por eso sostiene Comte que "el verdadero espíritu positivo consiste, ante todo, en ver para prever, en estudiar lo que es, a fin de concluir de ello lo que será" (Comte, 2007, p. 9).

La hipótesis de Comte es que una vez que la razón humana se ha circunscrito a su "dominio", es decir, a lo que solo le es posible conocer a la humanidad, entrará en un estado de "armonía mental, individual y colectiva" (Comte, 2007, p. 11). O sea, el estado positivo traerá consigo el orden y el progreso (Comte, 2007, p. 11). Pero aquí el orden y el progreso se explican, para el autor, por la disposición de los acontecimientos. En este caso las leyes de semejanza y de filiación que explican los estados de la existencia y el movimiento son, a su vez, en esta lógica, las que permiten dar cuenta del orden y el progreso -por coexistencia y sucesión-y, en este sentido, explicar y prever los fenómenos (Comte, 2007, p. 11). Así, la estática y la dinámica social manifiestan en sí mismas la armonía y el cambio social. Pero, al tiempo, son la expresión del "destino común" al que nos empujan las leyes sociales, a la "espontánea unidad de nuestro entendimiento" (Comte, 2007, p. 12) para hacernos hallar "la constancia en medio de la variedad" (Comte, 2007, p. 11). Y este fin de nuestro entendimiento humano solo puede ser alcanzado por la sociología, a la que Comte llama ciencia social o humana por antonomasia. Ese fin son los razonamientos humanos destinados a satisfacer las necesidades esenciales del hombre (Comte, 2007, p. 12). 
Ahora bien, para Comte la nueva ciencia social, la filosofía positiva, adopta, en contraposición a la metafísica, un punto de vista social en tanto que ella parte de que "el hombre no se desenvuelve aisladamente, sino en colectividad" (Comte, 2007, p. 13). Pero este punto de vista social es presentado por el autor como el sucedáneo, ahora posible y eficaz gracias al estado positivo, del "proyecto de asociación universal del cristianismo" de la Edad Media (Comte, 2007, p. 14). En otras palabras, la filosofía positiva es presentada por el autor como un proyecto de sociedad universal. Ahora el positivismo aparece, más que como una ciencia, como un proyecto de reforma social, y Comte como el Dante del siglo XIX. ${ }^{1}$ De este modo, la ciencia positiva se armoniza con el arte, es decir, se hacen compatibles y solidarios la teoría y la práctica, pues el positivismo no es únicamente un método de comprensión e indagación de la realidad natural y social, también es un proyecto político y moral centrado en "el mejoramiento continuo de su propia naturaleza, individual o colectiva, entre los límites que indica, como en todos los demás casos, el conjunto de las leyes reales"' (Comte, 2007, p. 15). Claro, este nuevo proyecto, al haber sido desplazado el estado teológico y el metafísico, ha de estar sustentado en un régimen político y social compatible con un estilo de vida industrial (Comte, 2007, p. 16). Así, la filosofía positiva, como nueva ciencia social y humana, viene siendo sinónimo de lo real, lo útil, la certeza, lo preciso. Pero, ante todo, es el antónimo de lo negativo en tanto que ella tiene por objeto primordial organizar la sociedad antes que destruirla (Comte, 2007, p. 20). Y, en tal sentido, su cometido tiene, entre otros propósitos, llevar las teorías morales y sociales al estado positivo. En últimas, esto solo significa que la filosofía positiva es, en la época de la Ilustración, la verdadera "revolución mental" que la revolución política² no pudo lograr (Comte, 2007, p. 24). E incluso anterior a la misma revolución política, pues su legado viene de Bacon y Descartes (Comte, 2007, p. 24).

\section{Segunda parte: superioridad social del espíritu positivo}

En la segunda parte de su obra, Comte evidencia con mayor holgura que su filosofía positiva es una respuesta a la crisis social de su época. Él la llama la "única salida intelectual" (Comte, 2007, p. 24) a la crisis social europea y francesa. Pero, ¿en qué consiste tal crisis? Comte, en forma abstracta, la caracteriza así:

La Gran Crisis final comenzó necesariamente cuando esta común decadencia, espontánea primero, luego sistemática, a la que, por otra parte, todas las clases, sin distinción, de la sociedad moderna habían contribuido de diversos modos, llegó por fin al punto de hacer universalmente irrecusable la imposibilidad de conservar el régimen antiguo y la necesidad creciente de un orden nuevo. (Comte, 2007, p. 24)

1 Pues Dante, en su tratado de Monarquía (2004), proponía un orden social universal cristiano pero sustentado en un poder temporal con la intención de dar fin a la anarquía social y política de la Europa de su tiempo. 
Pese a la manera tan genérica en que el autor presenta la crisis, bien podríamos estar tentados a sostener que el punto de quiebre de esa "común decadencia", como la llama el autor, es la Revolución francesa. Pero, en términos más estrictos, él la caracteriza como un estado de desorden o de desgobierno político (Comte, 2007, p. 25). De este modo, la salida a la crisis planteada por Comte es subsidiaria de su interpretación de la Revolución francesa. Por eso, al modo como lo planteó Kant (1998) en su momento, Comte piensa que la solución a la crisis social está en poner en suspenso la revolución política y darle paso a lo que él llama la "revolución mental", es decir, una revolución que se realice primero en "las ideas, para pasar luego a las costumbres y, en último término, a las instituciones" (Comte, 2007, p. 27). De este modo queda establecido, según la filosofía positiva, que primero está el orden y luego el progreso, siendo el primero la condición primordial del segundo y este último la finalidad del primero (Comte, 2007, p. 27). Esto, de paso, advierte que para Comte la causa de la crisis es ante todo "mental" (Comte, 2007, p. 27). Y al ser mental es, por sobre todo, moral (opiniones y costumbres) más que de carácter político o institucional (Comte, 2007, p. 27). Por eso la filosofía positiva está ligada al impulso elemental de la búsqueda de un orden moral como:

[...] una mera prolongación juiciosa, primero espontánea y luego sistemática, del orden natural que resulta, en cada caso, del conjunto de las leyes reales, cuya acción efectiva es modificable de ordinario por nuestra certera intervención, entre límites determinados, tanto más apartados cuanto más elevados son los fenómenos. (Comte, 2007, p. 27)

Así como se trata de la construcción de un nuevo orden moral que solo puede ser modificado dentro de ciertos límites que permiten las leyes naturales, de la misma forma se trata de un orden moral que tiene como finalidad el "sostener con energía el choque de las pasiones" (Comte, 2007, p. 33). Lo que indica que, expresado así, ese orden moral no privilegia la moral individual sino, al contrario, el deber de una moral colectiva, es decir, un sentimiento de carácter social (Comte, 2007, p. 34). Se trata, entonces, de la superación del desorden moral del antiguo régimen, es decir, el de la moralidad negativa del pensamiento dominante del Yo en la cual el nosotros no tiene cabida (Comte, 2007, p. 34). Como consecuencia, la conclusión es que el espíritu positivo, al ser social, inaugura la moral de la humanidad dejando atrás la moral negativa, individualista, del antiguo régimen. Por eso, Comte sostiene que "si la idea de sociedad parece todavía una abstracción de nuestra inteligencia, es, sobre todo, en virtud del antiguo régimen filosófico; pues, a decir verdad, es la idea de individuo a quien pertenece tal carácter, al menos en nuestra especie" (Comte, 2007, p. 35).

\section{Tercera parte: condiciones de advenimiento de la escuela positiva}

Ya ha quedado establecido que el proyecto positivista de Comte consiste en reemplazar con una revolución mental una anárquica revolución política e intelectual. Ahora bien, la realización de tal idea parte, por un lado, según el 
autor, de "consolidar todos los poderes actuales en manos de sus poseedores, cualesquiera que sean, y, por otro, a imponerles obligaciones morales cada vez más conformes a las verdaderas necesidades de los pueblos" (Comte, 2007, p. 37). También, de la necesidad de la universalización de la enseñanza del positivismo, pese a las naturales resistencias que pueda haber. Esta universalización es entendida por el autor como una "vulgarización total de los conocimientos reales" (Comte, 2007, p. 39). Ahora, como se ha dicho antes, si bien por un lado la enseñanza del positivismo pude tener opositores, por otro, Comte encuentra que quienes mejor están dispuestos a favorecer tal enseñanza es el "pueblo propiamente dicho" (Comte, 2007, p. 39), dada su condición particular. Si el pueblo es el más apto para acoger y "comprender la sociabilidad moderna", por ende, las clases altas y las élites intelectuales son las menos dispuestas por su espíritu teológico y metafísico más propio de una sociabilidad antigua (Comte, 2007, p. 40). Del mismo modo en que existen estas diferencias entre las clases ya señaladas, Comte advierte en el caso de la vida industrial los mismos antagonismos entre los empresarios y los obreros, estos últimos con la misma disposición de la clase popular hacia el espíritu del positivismo.

Es, por supuesto, claro que para Comte la enseñanza del positivismo es, ante todo, de carácter moral. De ahí su convicción, ligada a lo que él considera la causa de la crisis social de su época, de que el pueblo debe ser "indiferente a la posesión directa del poder político" sin dejar de renunciar nunca a "su indispensable participación continua en el poder moral" (Comte, 2007, p. 43). Su propuesta de revolución es la reforma moral y no política. Esa es su manera de criticar y pensar la Revolución francesa y sus consecuencias.

\section{Ciencia y utopía social}

\section{El estudio científico de la sociedad}

Hace ocho años apareció publicado el libro que lleva por título Auguste Comte. An Intellectual Biography de Mary Pickering (2009). Se trata de una rigurosa biografía sobre Comte y su desarrollo intelectual. En la introducción a esta obra, Pickering inicia afirmando que:

In the second half of the nineteenth century, criticisms of religion proliferated, threatening the foundation of Western thought and society. Historians of ideas usually highlight the publication of Charles Darwin's The Origin of Species in 1859 as the watershed moment in the erosion of the Bible's authority. However, five years before this important date, another major nineteenth-century thinker, Auguste Comte, had completed his four-volume Système de politique positive, which not only more aggressively attacked traditional religions as irrational and obsolete but offered a creative secular alternative, the Religion of Humanity. (Pickering, 2009, p. 1) 
La manera en la que Pickering da inicio a su biografía sobre Comte es reveladora, sobre todo para la discusión que vamos a emprender sobre el autor en lo que sigue de este trabajo. En la cita señalada, la autora de Auguste Comte. An Intellectual Biography sintetiza con perfecta maestría la tensión entre ciencia y utopía en la que se mueve el pensamiento y la obra de Comte. Una tensión que raras veces es comentada de frente, o que se matiza, para aumentar la fama de Comte como científico social. Tal como ocurre, por ejemplo, en los cometarios de Nisbet (2003) y de Giddens (2001) sobre el padre del positivismo. Esta primera parte de este apartado va a estar dedicado a delinear el lado científico del pensamiento de Comte para luego, en las dos partes siguientes, develar la tensión con su contraparte utópica.

Si bien, puede decirse, de una parte, que la modernidad del pensamiento científico se reafirmó plenamente con Newton y Kant. Con el primero por probar eficientemente la matematización de la naturaleza y con el segundo por dejar en claro los límites de la razón respecto de sus objetos de conocimiento. No puede negarse, de otra parte, que Comte es el Newton y el Kant del estudio sobre la sociedad y, en este sentido, el padre de una nueva ciencia. Tal vez el que mejor captó el genio de Comte, aunque luego tomará distancia de él (Giddens, 2001, p. 279), fue John Stuart Mill. De acuerdo con el filósofo inglés:

The fundamental doctrine of a true philosophy, according to $\mathrm{M}$. Comte, and the character by which he defines Positive Philosophy, is the following: --We have no knowledge of anything but Phaenomena; and our knowledge of phaenomena is relative, not absolute. We know not the essence, nor the real mode of production, of any fact, but only its relations to other facts in the way of succession or of similitude. These relations are constant; that is, always the same in the same circumstances. The constant resemblances which link phaenomena together, and the constant sequences which unite them as antecedent and consequent, are termed their laws. The laws of phaenomena are all we know respecting them. Their essential nature, and their ultimate causes, either efficient or final, are unknown and inscrutable to us. (Mill, 2005, p. 3)

Si echamos mano de las palabras de Mill, podemos decir que Comte se volvió a plantear la pregunta fundamental que inspiro a la ciencia moderna: ¿cuál es el límite la razón humana? ¿Qué nos está permitido conocer? La diferencia es que el pensador francés volcaba esta pregunta al conocimiento de los fenómenos sociales, y, dirigido a este nuevo objeto de estudio, se propuso desalojar de la comprensión de la sociedad cualquier tipo de explicación teológica y metafísica que apelaba a la imaginación y a las ideas antes que a la observación y a los hechos (Comte, 2007). Esto, por supuesto, implicaba una explicación de la sociedad desde principios inmanentes, o sea, desde las regularidades de su propia naturaleza. Es decir, desde las propias leyes naturales que la regulan. En tal sentido, estos principios inmanentes nos proporcionan un conocimiento al que podemos acceder por medio de nuestra observación y de nuestro 
intelecto, es decir, un conocimiento relativo y no absoluto de los fenómenos. Desde este punto de vista, la ruptura de Comte con la filosofía ilustrada que piensa la sociedad como el producto de una sumatoria de individuos, donde estos últimos son anteriores y analíticamente tienen prioridad sobre aquella, es más que evidente. Como afirma Nisbet:

No es apropiada para su paladar la concepción de la sociedad del Iluminismo, una colección de individuos cuyas instituciones son meras proyecciones de lo intraindividual, tampoco lo es la que popularizaran Bentham y sus prosélitos: un campo de batalla de intereses individuales encontrados. Para Comte, la sociedad es sustantiva y primaria, precede al individuo en lo lógico y en lo psicológico, y lo modela. Fuera de sus roles en la sociedad, el hombre tal y como lo conocemos no es siquiera concebible. (Nisbet, 2003, p. 86)

Es interesante, como muestra Nisbet, el modo en que Comte piensa la sociedad. Es del todo evidente que su modo de entenderla es una clara recuperación de la concepción organicista sobre la teoría de la comunidad desarrollada por Aristóteles en su Política. Ella, según el estagirita, es un todo compuesto de partes, donde el todo es anterior a las partes mismas (Aristóteles, 1996). Esta vinculación con Aristóteles no es infundada, basta ver el homenaje que le hace Comte a la Política del filósofo griego en su The Positive Philosophy, donde dice que "the name of Aristotle first presents itself, his memorable Politics being one of the finest productions of antiquity, and furnishing the general type of most of the works on that subject that have followed" (Comte, 2009a, p. 55). Así, su ruptura con sus contemporáneos significa en él una recuperación del modo de pensar la sociedad en el momento de la filosofía clásica griega. Por eso, cuando Comte sostiene en su Corso di filosofia positiva que "questo lavoro, sempre diretto da regole incontestabili,conduce quasi spontaneamente alla indicazione motivata dei principali perfezionamenti ulteriori, destinati soprattutto a liberare definitivamente la scienza reale da ogni indiretta influenza dell' antica filosofia" (Comte, 2008, p. 43), debe comprenderse que su principal contendor no es la antigua filosofía griega -por lo menos no la de Aristóteles-, sino la teoría sobre la sociedad elaborada por los teóricos del contrato y por los filósofos ilustrados iusnaturalistas.

Ahora bien, siguiendo lo argumentado en su Discurso sobre el espíritu positivo (2007), en A General View of Positivism Comte sostiene que:

The object of all true Philosophy is to frame a system which shall comprehend human life under every aspect, social as well as individual. It embraces, therefore, the three kinds of phenomena of which our life consists, Thoughts, Feelings, and Actions. Under all these aspects, the growth of Humanity is primarily spontaneous; and the basis upon which all wise attempts to modify it should proceed, can only be furnished by an exact acquaintance with the natural process. 
We are, however, able to modify this process systematically; and the importance of this is extreme, since we can thereby greatly diminish the partial deviations, the disastrous delays, and the grave inconsistencies to which so complex a growth would be liable were it left entirely to itself. To effect this necessary intervention is the proper sphere of politics. (Comte, 2009b, p. 8)

Por lo enunciado en la anterior cita se deduce que, aunque Comte rechaza la teoría según la cual la sociedad es un constructo artificial producto de la acción libre de los individuos, él no desconoce que la vida humana puede ser entendida tanto en su ámbito social como en el individual. Dicho esto, Comte parece querer diferenciar que su disputa no es con la vida humana individual, sino, más bien, con la teoría filosófica que explica la sociedad como el producto de una acción mecánica de agregación voluntaria de individuos. Claro, desde aquí se puede inferir que su punto de vista positivo, valga decir científico, de comprender la sociedad es entenderla como un hecho natural en el cual el individuo está integrado y desde el cuál este último solo puede ser explicado. Pero esta sutil diferencia no parece implicar en él una prioridad de la individualidad, o de la vida humana en su aspecto individual, sobre la sociedad como un todo. Más bien, parece dar la sospecha de que su física social se constituye, según expresión de Antimo Negri, en su Introduzione a Comte, como una "scienza totalitaria" (Negri, 1983, pp. 118-125).

Más allá de esto, lo importante son los tipos de fenómenos que a Comte le interesa indagar sobre la vida humana en cualquiera de sus manifestaciones. Estos fenómenos, como se dice en la cita anterior, son: "pensamientos, sentimientos y acciones". Con esto, el autor delinea y delimita con toda precisión su objeto de estudio. Y si aunamos a esto el modo en que ha conceptualizado la idea de sociedad, entonces es claro que para Comte la sociedad ha de ser estudiada como un fenómeno natural, a la manera como los biólogos estudiarían un ser vivo. Y, en tal sentido, "pensamientos, sentimientos y acciones" no pueden ser entendidos, científicamente, sino como relaciones orgánicas que únicamente pueden ser explicadas en relación con un todo que está regido por leyes naturales. Así, el estudio científico de la sociedad se inscribe en una comprensión de la sociedad como un fenómeno natural observable y anticipable. Porque solo hay explicación científica de algo cuando se es capaz de ver y prever. Esto último indica que, como fenómeno natural la sociedad (pensamiento, sentimientos y acciones), solamente puede ser modificada, en su decurso espontáneo, mediante un conocimiento preciso de su funcionamiento natural, lo cual implica las leyes que regulan su existencia. Ahora bien, para Comte, tal modificación solo procede en aras de evitar "las desviaciones". Para decirlo en los términos que años después usará Durkheim: las patologías. Clara evidencia de que, para Comte, en el uso de la metáfora organicista, la sociedad es como un cuerpo vivo que puede enfermarse y que, por ende, puede ser tratado preventivamente para evitarle sus dolencias. Esto puede llevar a inferir que el papel del científico social implica el doble carácter de la observación y la prevención como modelo de su explicación de la sociedad. En este sentido, el sociólogo, como el médico, tiene 
la doble función de diagnosticar y, al tiempo, prescribir con el fin de proveer un estado de mejoría al cuerpo social. Pero esta doble función se encuentra condicionada, obviamente, por las leyes naturales que ponen el límite de la agencia humana en relación con la sociedad. Antimo Negri en su Introduzione a Comte explica claramente este carácter de la ciencia de la sociedad en Comte:

La vie active di Comte, o la human agency di Stuar Mill, trova la maggiore espansione nel mondo umano e sociale. Ma questo stesso mondo, in quanto è connesso al mondo fisico, ha pur sempre un margine di immodificabilità. Un margine di immodificabilità ha, soprattutto, la natura umana, per il fatto che è física e chimica. E non si può modificare fino a vincere il destino di norte dell'uomo. È la scienza della vita, o la biologia, a probarlo; e si sa, ormai, che la biologia ha a che fare con fenomeni che, per quanto specificamente vitalo, sono anche quelli vincolati a leggi non trasgredibili, l'ignoranza delle quali fa perderé all'azione dell' uomo, nelcaso specifico l'arte medica, la sua base razionale: e va da sé che, perduta questa base, non solo l'arte medica, ma la stessa scienza biológica, che le è alle spalle, rimena in braccio alla teología e alla metafísica. (Negri, 1983, p. 93)

De este modo, el estudio científico de la sociedad es equiparado por Comte con el estudio científico de cualquier fenómeno natural. Aún en la relación de los límites de la libertad humana respecto del orden natural en sus diversos ámbitos.

\section{Individualismo Vs. sentimiento social}

En la primera parte de Comte After Positivism, Robert C. Scharff (2002) explica en detalle los diversos puntos epistemológicos y metodológicos que provocaron la ruptura intelectual entre John Stuart Mill y Comte. Sin embargo, no enuncia que una de las posibles divergencias entre los dos pensadores era su distinto modo de pensar la sociedad y, por supuesto, su relación con la libertad. Esto, claro está, no puede hacernos pasar por alto que Comte y Mill estaban de acuerdo en su postura antimetafísica de concebir la sociedad y la libertad humana. En este sentido, ambos pensadores estaban unidos en su ataque a las teorías iusnaturalistas y del contrato social. Teorías que Comte identificaba con el antiguo régimen y, por ende, con el estadio metafísico en su famosa ley de los tres estadios (Comte, 2007). Es decir, tanto Comte como Mill se identificaban en su apreciación de que la libertad fuera un derecho natural a la manera como lo había planteado, por ejemplo, Hobbes y sus continuadores. En tal sentido, ambos pensadores rechazaban la idea ilustrada de que la sociedad fuera el producto de un pacto social fundado en una supuesta libertad natural, anterior a la sociedad, y de carácter individual. Para ser más exactos, esta última parte, la de que la libertad fuese de carácter individual, no era rechazada por Mill. Y el que aceptara este supuesto implicó en él un modo de pensar la sociedad de forma contraria a Comte. Mientras el pensador francés se representaba la sociedad desde la metáfora organicista, es decir: un todo compuesto de partes donde el 
todo es anterior a las partes mismas, Mill seguía una explicación mecanicista de la sociedad como un todo compuesto por agregación de partes, donde las partes son anteriores al todo. Para Mill, la parte más pequeña de la que se compone la sociedad es el individuo. Pero este individuo aparece en primera instancia como un ser que no es espontáneamente social, pues su sociabilidad es producto del simple cálculo utilitario y, por supuesto, del derecho positivo del Estado que provee y garantiza la libertad individual de las personas. Para Comte, la parte más pequeña de la que se compone el todo es, a la vieja usanza aristotélica, la familia. En tal sentido, el hombre no es concebido como un individuo sino, más bien, como un ser social en quien la sociabilidad se da de forma espontánea, es decir, natural. En el capítulo V de su The Positive Philosophy (2009a), titulado "Social statics; or, theory of the spontaneous order Of human society", Comte deja en claro esta polémica con el utilitarismo de Mill y con las teorías iusnaturalista:

As every system must be composed of elements of the same nature with itself, the scientific spirit forbids us to regard society as composed of individuals. The true social unit is certainly the family, - reduced, if necessary, to the elementary couple which forms its basis. This consideration implies more than the physiological truth that families become tribes, and tribes become nations: so that the whole human race might be conceived of as the gradual development of a single family, if local diversities did not forbid such a supposition. There is a political point of view from which also we must consider this elementary idea, inasmuch as the family presents the true germ of the various characteristics of the social organism. Such a conception is intermediate between the idea of the individual and that of the species, or society. (p. 132)

Esto no nos puede llevar ingenuamente a plantear que Comte niegue la libertad humana. Su discusión aquí es netamente teórica. Pues su modo de razonar lo lleva a negar que la libertad humana se pueda explicar como un atributo individual de las personas. Más bien, su punto de vista es que la libertad se debe entender como una relación social. Coherentemente con sus postulados epistemológicos, su idea de la libertad es claramente sociológica y no metafísica. La libertad es un desarrollo espontáneo de las relaciones sociales orgánicas entre los hombres, es relacional. Expresado de otra manera, para Comte la cohesión social no se da por vínculos artificiales a la manera como la entendieron los teóricos del contrato y los utilitaristas. La cohesión social es, más bien, producto del natural "sentimiento social". En este sentido, para él no se puede pensar la moral como algo individual sino, al contrario, como un fenómeno social. Desde aquí es posible entender la centralidad que va a tener en la ciencia social moderna, como en Durkheim y Weber, la moral y la acción social como un fenómeno digno de investigación sociológica. La moral es, entonces, un fenómeno colectivo y no individual, de ahí que para comprender la acción de los individuos sea necesario empezar por comprender las leyes sociales que la regulan. Y es solo desde esta postura teórica que se puede comprender científicamente la libertad humana. 


\section{Comte el reformador social: de la ciencia a la utopía}

Llegados a este punto, es posible dar sentido a la articulación entre el Comte científico social y el Comte reformador social. Es decir, a la articulación entre ciencia y utopía en el pensador francés. Dos cosas que pudiesen parecer, a simple vista y en principio, contradictorias. Bien es cierto que, al ser una obra de síntesis, el Discurso sobre el espíritu positivo evidencia este desgarrador conflicto intelectual de Comte. La tesis que aquí se defiende es que este conflicto no está debidamente superado en la escritura o, mejor, en la narrativa que guía la trama de este famoso opúsculo del autor, pero, donde si está superado, es decir, conciliado, es en los propósitos tácitos de la filosofía positiva de Comte. Para decirlo en términos más lapidarios, Comte estaba consciente de que así como él se proponía la construcción de una sociología científica, es decir, observacional y descriptiva, también veía factible y absolutamente necesaria una sociología normativa. Una manera de sustentar esta idea es volver a situarse en el poder explicativo que tenía para Comte la metáfora organicista con la cual él se representaba la sociedad. La idea de que, como se afirmaba anteriormente, para Comte el sociólogo debía ser como el médico, en su doble función profesional de diagnosticar y, al tiempo, prescribir con el fin de proveer un estado de mejoría al cuerpo social, ya implicaba que a la sociología le era inherente una labor normativa, pues ella habría de tener dentro de sus funciones la de indicar cuál era el mejor régimen social posible para la humanidad.

En este orden de ideas es que se deben entender las críticas de Comte al estadio metafísico y su defensa de una moral individualista. Sin embargo, la cabal comprensión de esta crítica no puede darse si no se afirma sobre un hecho histórico que le de sustento argumentativo e histórico. Este hecho es la Revolución francesa y la manera en que Comte experimentó y pensó sus consecuencias. A este respecto, son muy dicientes, por ejemplo, las palabras de Comte a Benedetto Profumo el 26 de diciembre de 1851. Nuestro autor le dice que "the unexpected coming of a true temporal dictatorship alters very happily our republican situation and consequently the entire Occidental situation" (Comte, 1973). Estas palabras de Comte a su amigo son una de tantas evidencias que nos permiten sostener que, como Tocqueville, Comte no compartió la Revolución francesa por considerar que la ideología revolucionaria conducía a los franceses a la servidumbre en la igualdad más que a la libertad. A este respecto, vale la pena leer el primer capítulo de la excelente biografía sobre Comte de Mary Pickering. En ella, la autora recrea la manera en que el autor vivió la Revolución, sus efectos y los temores y esperanzas que albergaba sobre tan dramática situación. Basta con leer el siguiente extracto de la biografía de Pickering para dimensionar lo que pasaba por la cabeza de Comte:

Like many others in France, Comte seemed to be increasingly worried about the political situation as chaos worsened after the Revolution of 1848 and the elections for the Assembly and the presidency approached in 1852. He imagined that the increasing anarchy weakened the central power, while the Assembly became more omnipotent as it governed 
by legislative committees. He hoped that the Parisian workers would be disabused of their "last metaphysical illusion," that of the importance of representative government, and that they would dismiss the Assembly with the "tacit approval of the provinces." Positivism could profit by presenting itself as the "unique refuge" of people worried about the family and property, which were "menaced by all the metaphysical tendencies" and "compromised by theological obstructions. (Pickering, 2009, p. 14)

De este modo, el positivismo de Comte puede ser leído e interpretado como una reacción crítica al estado de cosas sociales que construyó la Revolución francesa, como un rechazo de la ideología democrática de sus protagonistas y de sus filósofos, entre ellos Rousseau, que condujo a la guillotina y al terror, y, fundamentalmente, al despotismo al que llevó, según Comte, el "dogma de la libertad de conciencia" de los revolucionarios franceses. Por lo menos así lo hace saber Comte en su The Positive Philosophy, obra en la cual afirma que:

This is the rallying-point of the revolutionary doctrine, to which all orders of minds have come up, - the proud and the humble, the wise and the weak, -those whose other opinions were compatible with this dogma, and those who unconsciously held views of an opposite order. The impulse of this emancipation was irresistible; and the revolutionary contagion was, in this one respect, universal. It is a chief characteristic of the mind of society in this century. The most zealous partisans of the theological polity are as apt as their adversaries to judge by their personal knowledge; and those who, in their writings, set up as defenders of spiritual government, recognize, like the revolutionists whom they attack, no other supreme authority than that of their own reason. (Comte, 2009a, p. 13)

Cualquier parecido con el Tocqueville de El antiguo régimen y la Revolución no es una simple coincidencia. Claro, no está en el propósito de este trabajo plantear una semejanza forzada entre estos pensadores franceses, que además fueron contemporáneos. A todas luces Comte, por su modo de pensar, puede ser ubicado como un pensador netamente conservador, a diferencia de Tocqueville. La razón de esto estriba en que las críticas de Comte a la libertad individual son más radicales que las de Tocqueville. Para el padre del positivismo la libertad individual, aquella que defendían los revolucionarios franceses con su ideología democrática, era el principio y la causa de la disolución del orden social. Si algo, para él, debilitaba y corroía la cohesión social era ese tipo de libertad ideológica. Por eso planteaba su positivismo como un programa de reforma social para un mundo mejor, como una salida a la crisis planteada por el individualismo que atentaba contra el orden social colectivo. No en vano lo que su positivismo proclama, en el fondo, antes que una revolución política, es una revolución de las costumbres. O, como acostumbra decirlo hasta el cansancio en su Discurso sobre el espíritu positivo, una "revolución mental": 
Tal es el doble fin filosófico de la elaboración fundamental, a un tiempo especial y general, que me he atrevido a emprender en la obra citada al comienzo de este Discurso: los más eminentes pensadores contemporáneos la juzgan así bastante acabada para haber ya puesto las verdaderas bases directas de la revolución mental entera, proyectada por Bacon y Descartes, pero cuya ejecución decisiva estaba reservada a nuestro siglo. (Comte, 2007, p. 24)

Como para Tocqueville, esa revolución, según Comte, era anterior a la revolución política de la Revolución francesa, y, en este sentido, la revolución política no era más que una desviación social que debía ser corregida de forma perentoria por el positivismo. Así, el pensamiento social del Great Priest of Humanity (Pickering, 2009, p. 526), al vincular la sociología con la humanidad (Gane, 2006, pp. 86-102) tiene el propósito y la necesidad de construir un ideal social, al mejor estilo de Platón. Por lo cual no sería acertado decir que la ciencia sociológica de Comte termina donde empieza su utopía social. Es, al contrario, más apropiado sostener que en el autor la utopía social es la consecuencia natural de su ciencia sociológica.

\section{Conclusión: Comte frente a Adorno y Horkheimer}

En este apartado vamos a dedicar unas pocas palabras a la crítica de Adorno y Horkheimer al positivismo comtiano. Para estos dos pensadores de la Escuela de Frankfurt, la sociología de Comte no es un saber emancipador de la humanidad. En La sociedad. Lecciones de sociología ellos sostienen que "la sociología positiva, en el sentido de Comte, considera como tarea propia el reconocimiento de las leyes naturales que todavía son concebidas como inmutables. Lo que importa es la exactitud rigurosa de la comprobación, y no una verdad absoluta o la sociedad justa" (Adorno y Horkheimer, 1969, pp. 12-13). Aún más, sostienen que para Comte la sociedad "es objeto de simple observación, no de admiración o condena" (1969, p. 13). Estos dos pensadores de Frankfurt interpretan al autor del Discurso sobre el espiritu positivo como una mente en la que, por pertenecer al mundo ilustrado, ya está menguada su "fe en el autoperfeccionamiento de la sociedad humana, realizado mediante la acción pedagógica" $(1969$, p. 14). Lo que supone que la sociología, desde sus orígenes en Comte, renunció por completo al elemento normativo propio de las doctrinas de la sociedad de los filósofos, desechando así todo tipo de construcción teleológica e idealizada del orden social. De un modo sintético, Adorno y Horkheimer expresan su comprensión del espíritu de la sociología de Comte así: "el impulso de la posible transformación del ser por obra del deber ser, propio de la filosofía, dejaba paso al sobrio celo del que acepta el ser como deber ser" (1969, p. 17). Con lo cual identifican su ciencia de la sociedad con un saber falto de independencia para la meditación y la crítica; un saber conformista con la realidad por tener su horizonte restringido a los "fenómenos exteriores".

Lo anterior pone en evidencia que Adorno y Horkheimer pasan por alto, en su crítica, que en el pensamiento de Comte conviven, al tiempo, la figura del 
científico y del reformador social -que es la tesis que hemos sostenido a lo largo de estas páginas-. Así, la ruta de lectura propuesta en este trabajo nos ha permitido llegar a la idea de que la utopía social en Comte es la consecuencia natural de su ciencia sociológica. Como fruto de este modo de análisis del autor, esta idea es por sí misma importante, ya que nos permite confrontar la lectura que han elaborado tanto los practicantes y defensores del positivismo comtiano, como la que han construido sus detractores -especialmente la escuela de Frankfurt, de la mano de Adorno y Horkheimer-. Es decir, nos permite salirle al paso a la tesis de que en Comte la sociología no es un saber emancipador de la humanidad. $\mathrm{O}$, lo que es lo mismo, que desde sus orígenes mismos, la sociología, como ciencia de la sociedad, renunció a todo tipo de formulaciones o inferencias normativas, se prohibió a sí misma pensar críticamente el orden social existente y, con esto, dejó atrás el "impulso", natural en la filosofía, "de la posible transformación del ser por obra del deber ser" para quedarse solo con el "sobrio celo del que acepta el ser como deber ser" (Adorno y Horkheimer, 1969, p. 17).

Pero más allá de la crítica de los pensadores de Frankfurt, lo cierto es que, como suele pasar a menudo en la historia de las ideas con la interpretación de los autores clásicos, tanto los defensores y seguidores de Comte y su positivismo como los detractores del mismo han terminado por construir una comprensión parcializada de él y de su sociología. Sin embargo, lo más paradójico de esta interpretación, paradigmática ya, es que, por vía positiva o negativa, a favor o en contra de este pensador, nos muestra a un Comte que piensa y enseña que el conocimiento científico de la sociedad, para ser tal, solo debe entender a esta última como un objeto de mera observación y nunca como un objeto de valoración moral.

En este sentido es que afirmamos que sus defensores y seguidores han hecho a un lado la sociología normativa de Comte, su proyecto de utopía social, como devaneos sin importancia del autor, con el fin de darle únicamente relevancia y sentido a su proyecto de sociología científica, con lo cual han echado por la borda un aspecto clave del pensamiento del pensador francés. Los segundos, sus detractores, y aquí apelamos específicamente a Adorno y Horkheimer, también se empañaron en negar la existencia del proyecto de utopía social en el autor con el fin de presentarnos a un padre fundador que enseño a hacer "sociología sin sociedad" (Adorno y Horkheimer, 1969, p. 20).

Nuestro esfuerzo aquí a consistido, entonces, en señalar que la sociología de Comte nunca abandona la búsqueda de una "sociedad justa", y que ese propósito es la consecuencia natural de su proyecto de sociología científica. Por eso, es pertinente afirmar que en Comte su positivismo o su sociología no son incompatibles con la utopía social. Que la sociedad, para él, no es solo un objeto de observación, sino, también, de admiración y condena. Que su sociología es, por su propia naturaleza, un saber emancipador de la humanidad. Ya es hora de advertir esto que se ha querido negar, y de sacarle provecho. 


\section{$\mathbf{R}_{\text {eferencias }}$}

\section{Obras de Comte}

Comte, A. (1972). La science sociale. Paris: Éditions Gallimard.

Comte, A. (1973). Correspondance générale et confessions. En P. E. de Berrêdo Carneiro, P. Arnaud, P. Arbousse-Bastide, y A. Kremer-Marietti (Eds.). Paris: Ecole des Hautes Etudes en Sciences Sociales.

Comte, A. (2007). Discurso sobre el espíritu positivo. Madrid: Alianza Editorial.

Comte, A. (2008). Corso di filosofia positiva. Milano: Editore Mondadori.

Comte, A. (2009a). The Positive Philosophy of Auguste Comte. New York: Cambridge University Press.

Comte, A. (2009b). A General View of Positivism. New York: Cambridge University Press.

\section{Otros autores}

Adorno, T., y Horkheimer, M. (1969). La sociedad. Lecciones de sociología. Buenos Aires: Editorial Proteo

Alighieri, D. (2004). Monarquía. Madrid: Editorial Tecnos.

Aristóteles (1996). Política. Barcelona: Editorial Altaya.

Descartes, R. (2001). Discurso del método. Madrid: Editorial Libsa.

Gane, M. (2006). Auguste Comte. London and New York: Routledge.

Giddens, A. (2001). El positivismo y sus críticos. En T. Bottomore, y R. Nisbet, Historia del análisis sociológico. Argentina: Amorrortu Editores.

Kant, E. (1998) Si el género humano se halla en progreso constante hacia mejor. En E. Kant, Filosofía de la historia. México: Editorial Fondo de Cultura Económica.

Kuhn, T. S. (1975). La estructura de las revoluciones científicas. México: Editorial Fondo de Cultura Económica.

Maquiavelo, N. (1998). El Príncipe. Madrid: Alianza Editorial.

Marías, J. (2007). Prólogo. En A. Comte, Discurso sobre el espíritu positivo. Madrid: Alianza Editorial. 
Mill, J. S. (2005). Auguste Comte and Positivism. New York: Marc D’Hooghe.

Negri, A. (1983). Introduzione a Comte. Roma-Bari: Editori Laterza.

Nisbet, R. (2003). La formación del pensamiento sociológico (tomo I). Argentina: Amorrortu Editores.

Pickering, M. (2009). Auguste Comte. An Intellectual Biography (Volume III). New York: Cambridge University Press.

Scharff, R. C. (2002). Comte After Positivism. U. K.: Cambridge University Press. 